\title{
Healthiness of foods on promotional flyers of fast-food outlets located within Accra-based shopping malls
}

\author{
Patience Tsrah ${ }^{1}$, MPH; Wilhemina Quarpong ${ }^{1}$, MPH; Amos Laar ${ }^{1 *}$, Ph.D \\ ${ }^{1}$ Department of Population, Family and Reproductive Health, School of Public Health, \\ University of Ghana, Accra Ghana \\ *Corresponding Author: Amos Laar, E-mail: alaar@ug.edu.gh
}

\section{ABSTRACT}

\section{Background}

It is argued, rather controversially, that shopping malls and fast food outlets promote unhealthy foods more heavily than healthy ones. Promotional flyers are one of many strategies usually deployed to influence purchasing behaviours.

We aimed to assess the healthiness of foods on promotional flyers of food outlets located within shopping malls in Ghana's capital city, Accra.

\section{Methods}

We conducted a content analysis of promotional flyers obtained from all fast-food outlets located within Accra-based shopping malls. Food promotions on flyers $(n=32)$ were sampled using a composite week sampling technique. Collected via mystery shopping, all promoted foods were evaluated for healthiness. Healthy foods/food groups were defined as products which help prevent diet-related non-communicable diseases (NCDs).

\section{Results}

All $(100 \%)$ of the foods $(n=79)$ on the promoted flyers were unhealthy-comprising high sodium/saturated fats $(\mathrm{n}=36)$, high sodium exclusively $(\mathrm{n}=40)$ and high in added sugar foods $(n=3)$. These unhealthy foods were greatly discounted (average percentage discount was 27.5\%). This price benefit (54.0\%) and puffery size (34.0\%) were the major claims associated with the promoted foods.

\section{Conclusions}

Our data show that food outlets within Accra-based shopping malls promote via flyers unhealthy food items that are greatly discounted. This strategy may influence purchasing behaviour and consumption. The causal relationship between the promotion of unhealthy foods and NCDs deserves evaluation in Ghana. 


\section{INTRODUCTION}

Globally, the prevalence of obesity has soared since 1975 (Abarca-Gómez et al., 2017). In 2016, nearly two billion adults were estimated to be overweight (>650 million of whom were obese) and over 340 million children and adolescents aged 5-19 years overweight or obese (AbarcaGómez et al., 2017). Ghana is at an advanced stage of the nutrition transition, experiencing rapid urbanization, and increasing obesity and other diet-related non-communicable disease (NCDs) (Ghana Statistical Service et al., 2015). Within two decades, the prevalence of overweight/obesity among Ghanaian women increased from 10\% in 1993 to 40\% in 2014 (Ghana Statistical Service -GSS and Macro International, 1994; Ghana Statistical Service et al., 2015). A more recent systematic review by Ofori-Asenso et al. (2016) shows consistent increases in overweight and obesity among Ghanaian adults ( $\geq 18$ years) over the period of 1998 to 2016. According to this review, 43\% of Ghanaian adults are overweight, the prevalence being higher among urban dwellers, women, and residents in the Greater Accra Region.

There is evidence that these global increases in obesity rates are due in part to unhealthy food environments (Abarca-Gómez et al., 2017; Freudenberg, 2014; Kessler, 2010). The food environment, defined by Swinburn et al. (2013), as "the collective physical, economic, policy and sociocultural surroundings, opportunities and conditions that influence people's food and beverage choices and nutritional status' has a significant impact on what is consumed. Often referred to as obesogenic environments (availing and promoting more unhealthy foods compared to healthy foods and thus contributing to overweight and obesity), large food retail outlets such as shopping malls, supermarkets, chained restaurants, and eateries qualify (Gauthier and Krajicek, 2013; Umberger et al., 2015; León-Muñoz et al., 2016). Environmental factors such as the availability of products and the ease of obtaining already-prepared food from these outlets have made them popular with consumers. Meanwhile, these outlets (shopping malls, supermarkets and chained food restaurants) are fast replacing traditional fresh food markets as a major source of food in most countries; including in developing countries (Parfitt et al., 2010).

There are many factors that inform consumers' choice of a food outlet: convenience, outlet atmosphere, branding, and marketing (Robert Wood Johnson Foundation and The Food Trust, 2011). One main way food industries influence consumer's choice of foods is through marketing. Food industries spend billions of dollars on persistent and pervasive marketing of the foods they sell via various strategies. These strategies, collectively referred to as 'the four Ps' of marketing - Product, Placement, Price and Promotion (Robert Wood Johnson Foundation and The Food Trust, 2011) greatly affect food purchases within food outlets. Pricing has the greatest influence, especially in developing countries (Steenhuis, Waterlander, and de Mul 2011). It has been shown that varied pricing mechanisms such as discounting are used to stimulate demand for both unhealthy (Gittelsohn et al., 2017) and healthy food products (Robert Wood Johnson Foundation and The Food Trust, 2011). Such pricing attractions are sometimes communicated via promotional flyers.

Food promotional flyers as a marketing tool to significantly attract consumers into stores has been studied (Ziliani and Bellini, 2003) but this has been little studied in developing countries. According to Ziliani and Ieva (2015) the use of flyers to distribute and communicate supermarket food promotion has been acknowledged as an important tool for attracting consumers into stores, although Gittelsohn and colleagues argue that most of these promote consumable products which are ultra-processed, energy dense, ready-to-eat, and normally without nutritional value (Gittelsohn et al., 2017).

We aimed to assess the healthiness of foods on promotional flyers of fast-food outlets within all major shopping malls in Accra. Specifically, the data presented provide answers to the following questions: How healthy are the foods that fast-food outlets within shopping malls promote on 
their flyers? How large is the price discount for foods on promotional flyers? What types of claims are included on these promotional flyers?

\section{METHODS}

\section{Study design and summary of field procedures}

This was a cross-sectional study carried out in all shopping malls located in Ghana's capital city, Accra. The operational definition for a shopping mall or a shopping complex in respect to this study is a large indoor shopping centre, with clearly marked department stores as well as a cluster of fast-food outlets and restaurants. Malls or shopping centres with a retail space of greater than 10,000 square metres were included in the study. Of seven shopping malls in Accra at the time of the study, four fit the study's inclusion criteria. The capacities of the included malls as per the 2019 Euromonitor Report are as follows: The Accra mall (20,619 sq m retail space) on Spintex road, Junction mall (12,000 sq m retail space) at Nungua, Achimota mall (14,622 sq m retail space) at Achimota and West-hills mall at new Weija, the largest shopping centre in the country with over 27,000 square metres of retail space (Euromonitor International, 2019). The selected shopping malls were all located in urban neighbourhoods in the Greater Accra Region and each had at least seven fast-food outlets and restaurants. All fast-food outlets within the shopping malls were visited. Using the composite week sampling technique (Riffe et al., 1998; Laar, 2010), 32 printed promotional flyers were sampled from these outlets. This involved visiting each shopping mall once per week for a period of 8 weeks from Monday, $4^{\text {th }}$ June to Monday, 30 ${ }^{\text {th }}$ July 2018. This resulted in a total of 8 visits, comprising 6 weekdays and 2 weekend days All shopping malls were visited on the same day each week. During each visit, trained mystery shoppers obtained printed promotional flyers from fast food outlets within each shopping mall. Mystery shopping, (also referred to as secret, phantom consumer shoppers) is a form of a form of participant observation, where researchers pretend to be real customers or potential customers so as to obtain relevant information from shop attendants. Content analysis of the 32 promotional flyers was done. Advertisements on flyers $(n=171)$ that were not sales promotions for food were excluded. The food categories used were adopted from the International Network for Food and Obesity NCDs Research Monitoring and Action Support (INFORMAS) Protocol. Details of this Protocol have been published elsewhere (Kelly et al., 2013).

\section{Assessing healthiness of promoted foods and beverages}

All promoted foods were evaluated according to whether they were likely to have a positive effect on preventing diet-related NCDs. For example, fruits, vegetables, whole grain food products, fat-free and low-fat dairy products, lean cuts of meats and poultry and seafood were considered healthy. Healthy beverages included fat-free or low-fat milk and unsweetened milk products, unsweetened fortified soy beverages and other lactose-free products, $100 \%$ juice, and water. Unhealthy foods on the other hand were those foods which contained added sugar such as cakes, cookies, sweet rolls, pastries, doughnuts, brownies, pies, cobblers, candy, dairy desserts, ice cream, energy drinks, and soft drinks or; saturated fatty acids such as cream, cheese, whole milk, beef ribs, sausage, and poultry skin); or high sodium foods such as pizza, casseroles, burgers, sandwiches, pepperoni, and flavoured/fried rice.

\section{Price discounts associated with foods and beverages on promotion}

Original prices of foods and beverages on promotion were recorded from the promotional flyers, and where unavailable, collected from shop attendants and confirmed from available printed store 
menus. This information was used to determine price discounts associated with foods on promotion.

\section{Claims associated with foods and beverages on promotion}

We recorded all claims associated with the promoted foods listed on the leaflets. Claims were assigned to five categories: health claims, new brand development claims, price benefit claims, puffery benefit claims (using and exaggerating the size of products to entice consumers), and convenient benefit claims.

\section{Data Analysis}

Data analyses were conducted using IBM SPSS Statistics version 17.0. Descriptive statistics such as absolute and relative frequencies were applied to characterize the data. Frequencies and percentages were computed for the different categories of foods and beverages on promotion. The average percentage discount for food items on promotion and average percentage discount for overall ad category for promotions were also determined.

\section{Ethics}

Ethical approval for this study was granted by the Ghana Health Service Ethical Review Committee (Approval number: GHS-ERC075/12/17).

\section{RESULTS}

\section{Characteristics of promotional flyers}

We located 250 food advertisements on the 32 flyers collected, of which 79 were food promotion adverts. Table 1 provides a general description of the 32 food promotional flyers. More than half (56\%) of food items on promotion during the study period did not have specific promotion days. A little over $20 \%$ of the promotions run from Mondays through to Thursdays. A total of 11 food outlets with discounted food items were identified. These food outlets were open for at least 10 hours (opened between 07:00-09:00 am and closed between 05:00-09:00 pm). Most of the promotional flyers were obtained from Pizza Inn, Chicken Inn, Pizza Hut, and KFC. Most promotions (72\%) required the purchase of multiple food items. See Table 1.

\section{Healthiness of food items on promotion}

The different food items on promotion in the flyers and their healthiness are presented in Table 2. Twenty-five out of a total of 79 food items promoted were pizza, making pizza promotions the most (32\%) frequently observed, followed by chicken, chips and coke combination (30\%). The least promoted food items were French fries (1.3\%), and pizza, sauce and cheese combination (1.3\%). All the 79 foods (100\%) promoted via flyers were unhealthy - comprising high sodium/saturated fats $(n=36)$, high sodium exclusively $(n=40)$ and high in added sugar foods $(n=3)$ See Table 2.

\section{Price discounts associated with foods and beverages on promotion}

Table 3 shows the average percentage discount on the different food items that were on promotion. French fries were given for free (at 100\% discount), as an incentive for buying any regular food item on the menu. Naked fries such as potato chips or yam chips (43\%); ice cream (33\%); pizza, sauce and cheese (32\%) were similarly discounted. The foods were greatly discounted (average percentage discount was 28\%). After assessing the food items in the ads, 50.6 percent were discounted in the high sodium exclusive category, closely followed by the high sodium / saturated fats category (46\%). 
Table 1: Characteristics of promotional flyers $(\mathrm{N}=32)$

\begin{tabular}{lll}
\hline Variables & Frequency & Percent \\
\hline Day of promotion & & 22 \\
From Monday-Thursday & 7 & 13 \\
From Monday-Wednesday & 4 & 9.4 \\
Mondays Only & 3 & 56 \\
Not specified & 18 & \\
Shopping Mall & & 25 \\
Accra Mall & 8 & 25 \\
Junction Mall & 8 & 25 \\
Achimota Mall & 8 & 25 \\
West Hills Mall & 8 & 16 \\
Shop Name & & 3.1 \\
KFC & 5 & 6.3 \\
Chicken Inn and Creamy Inn & 1 & 6.3 \\
Barcelos & 2 & 13 \\
Pizza Inn & 2 & 6.3 \\
Chicken Inn & 4 & 19 \\
Creamy Inn & 2 & 22 \\
Pizza Hut & 6 & 3.1 \\
Pizza Inn and Chicken Inn & 7 & 6.3 \\
Pizza Inn and Creamy Inn & 1 & 100 \\
Others (Basilissa and Steak) & 2 & 100 \\
Open Hours - Morning (07:00 to 9:00) am & 32 & 28 \\
Closing Hours - Evening (05:00 to 09:00) pm & 32 & 72 \\
Type of Promotion & & \\
Single Item Promo & 9 & \\
Multi-Item Promo & 23 & \\
\hline
\end{tabular}

Table 2: Healthiness of food items on promotion $(N=79)$

\begin{tabular}{llll}
\hline Food item on promotion & Frequency & Percentage & Healthiness \\
\hline High sodium/saturated fats foods & $\mathbf{3 6}$ & $\mathbf{4 6}$ & Unhealthy \\
Chicken, chips, coke & 23 & 30 & Unhealthy \\
Chicken, chips, salad, coke & 3 & 3.8 & Unhealthy \\
Chicken, fried rice & 8 & 10 & Unhealthy \\
Chicken, rice/chips, coke & 2 & 2.5 & Unhealthy \\
& & & \\
High sodium foods & $\mathbf{4 0}$ & $\mathbf{5 1}$ & Unhealthy \\
French fries & 1 & 1.3 & Unhealthy \\
Naked fries & 2 & 2.5 & Unhealthy \\
Pizza & 25 & 32 & Unhealthy \\
Pizza, coke & 4 & 5.1 & Unhealthy \\
Pizza, coke, chips & 3 & 3.8 & Unhealthy \\
Pizza, fries & 4 & 5.1 & Unhealthy \\
Pizza, sauce, cheese & 1 & 1.3 & Unhealthy
\end{tabular}



Added sugar foods
3
3.8
Unhealthy
Ice cream
3
3.8
Unhealthy

\section{Claims associated with foods and beverages on promotion}

As displayed in Figure 1, claims that were associated with food items promoted in all the four major shopping malls in Accra were mostly (54\%) price benefit claims and puffery size benefit claim (34\%). Claims that referred to convenience and the availability of new brands were $4 \%$ and $8 \%$ respectively.

Table 3: Average Percentage Discount for Food Items on Promotion

\begin{tabular}{ll}
\hline Name of food item on Promotion & Average Percentage Discount \\
\hline High sodium/saturated fats foods & $\mathbf{2 3}$ \\
Chicken, chips, coke & 31 \\
Chicken, chips, salad, coke & 16 \\
Chicken, fried rice & 23 \\
Chicken, rice/chips, coke & 22 \\
& \\
High sodium foods & 36 \\
French fries & 100 \\
Naked fries & 43 \\
Pizza & 27 \\
Pizza, coke & 17 \\
Pizza, coke, chips & 9.7 \\
Pizza, fries & 25 \\
Pizza, sauce, cheese & 32 \\
& \\
Added sugars foods & 33 \\
Ice cream & 33 \\
Total & \\
\hline
\end{tabular}

Figure 1: Claims Associated with Products

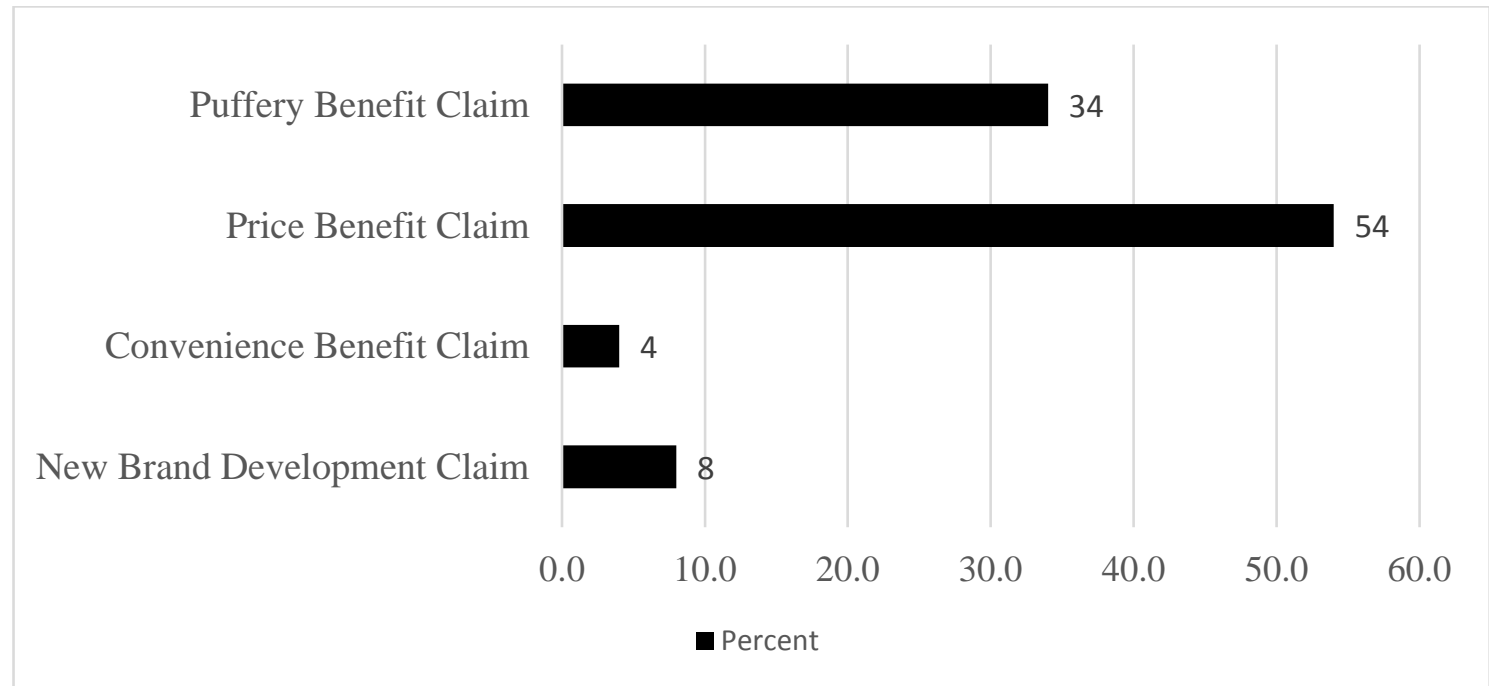




\section{DISCUSSION}

Food advertisements displayed on flyers may play a significant role in influencing consumer behavior towards the type of food purchased. Findings from our study indicate that fast food outlets within the shopping malls visited use every opportunity during the week to market greatly discounted unhealthy foods. Our study also reveals a long exposure time of consumers to the promotion of these unhealthy foods, evidenced by the long opening hours of the food outlets that displayed these foods on promotional flyers.

\section{Healthiness of Foods on Promotional Flyers}

Several studies unearth the health-related problems that arise with the eating of unhealthy foods. Some of these life threatening health problems are hypertension, type II diabetes, heart diseases, infertility and several forms of cancers (Jiang et al., 2016; Naicker et al., 2015).

The current study found that $100 \%$ of the food items on promotion were unhealthy. This confirms the general assumption that large food retail outlets (such as chained restaurants, supermarkets and shopping malls) are obesogenic environments - availing and promoting more unhealthy foods compared to healthy foods, thus contributing to overweight and obesity. Other studies have reported similar unhealthy food promotions via flyers. For instance, Ravensbergen et al. (2015) reported a prevalence of $70 \%$ unhealthy foods on promotional flyers obtained from outlets in the Netherlands, while Chapman et al. (2006) reported 82\% unhealthy foods in their study in Australia . It has been reported that there is higher marketing (Bell et al.,2013), and patronage (Payab et al., 2015) of unhealthy foods in developing countries than in developed countries.

In the current study, high sodium/saturated fats foods were the most heavily promoted (36/79). High sodium diets, according to Farquhar et al., (2015), can cause a lot of devastating problems that go beyond raising blood pressure, to affecting target organs in the body such as the heart, kidney and the brain. There is already a high prevalence of overweight and obesity in the study area (Ofori-Asenso et al., 2016).

\section{Price Discounts for Foods on Promotional Flyers}

Our data show that not only were the food items on promotion unhealthy, they were greatly discounted (average discount 27.5\%). Prices affect consumers purchasing decisions, especially in a low- or middle-income country (Payab et al., 2015). Existing data are suggestive that, Ghanaian consumers are influenced by product price (cost), time (convenience), adverts, ingredients, taste and appearance than healthiness (Ababio et al, 2012; Hayford et al, 2015; Darkwa, 2014). Thus cash incentives or discounts for healthy foods could be most effective policy to reduce unhealthy food consumption (Flores and Rivas, 2017).

Smaller food outlets have more expensive foods (healthy or unhealthy) (Caspi et al., 2017) but the lower prices in larger food outlets cause more harm to consumers because shoppers are compelled to buy more products to achieve discounts, especially when the product is found to be unhealthy (Ravensbergen et al., 2015). In the present study, consumers were encouraged to buy more than one unhealthy food product in order to receive a discount (72\% of discounted items required purchase of multiple food items). While a single unhealthy meal may not cause disease, excess weight gain and NCDs may result from routine consumption of unhealthy foods (Hill et al., 2012).

\section{Claims Associated with Food products Promoted in the Flyers}

This study identified price benefit claims, puffery size benefit claims, new brand development claims and convenience claims to be associated with the foods on promotion. Supposing that these strategies are successful at influencing consumers in the study setting (where all foods on 
promotion were unhealthy), then, consumers who obtain foods from these shopping malls may consume more unhealthy foods linked to obesity and NCDs. However, this assumption is only speculative as the association between the use of such claims and purchase of promoted foods was not measured in this study. Nevertheless, some studies have reported that these strategies are successful and are indeed linked to a greater purchase of food items that have such associated claims compared to those without such claims (French, 2003). Large companies are likely to utilize marketing research to guide their decisions on promotional expenditures, so if this assumption were incorrect, such promotion would likely end.

One important finding of this study was the absence of health claims associated with the foods on promotion. This confirms that indeed, healthy foods were not promoted. A similar study conducted in Brazil also identified price benefit claims, as well as convenience claims, to be associated with the promotion of ultra-processed food items and beverages (Machado et al., 2017).

\section{Strengths and limitations}

Our study had some limitations. The purposive sampling of larger shopping malls in Accra excludes other shopping malls, supermarkets, minimarts, wet and open markets that a good number of the residents patronize. Nevertheless, the four major malls in Accra are currently not only the largest shopping centres in the city, but also attract important demographics such as the young, middle, and upper class who are disproportionately predisposed to obesity. In addition, we used a robust data collection approach employing the use of composite week sampling and mystery shopping approaches, both of which reduce the likelihood of biases (Riffe et al., 1998).

\section{CONCLUSIONS}

Our study has found that fast food outlets within Accra-based shopping malls constantly promote unhealthy food items in large quantities, at greatly discounted prices. This practice may influence consumers to buy and consume, to a great extent, the unhealthy foods promoted. Subsequently, consumers who patronize, and consume the unhealthy foods on promotion may suffer serious health consequences, including obesity and other diet-related NCDs. Further research is needed to evaluate the causal link between unhealthy food promotion activities within food outlets and the development of NCDs.

In the meantime, there is a need to intensify local population promotion of healthy eating and to encourage healthy food environments to prevent diet-related NCDs. , Government should take action to create systems to support healthy food provisioning and retail environments by developing and implementing policy frameworks and structures that are specifically designed and placed to regulate the type of food sold or promoted within congregate areas such as malls-based food outlets. One counterstrategy to the marketing of heavily discounted unhealthy foods is a heavy value-added tax on unhealthy foods, which may discourage food outlet managers from placing discounts on them.

\section{Declarations}

\section{Availability of data and materials}

Study dataset available for deposition in a public repository if needed

\section{Competing interests}

All authors declare no competing interests

\section{Funding}

The study was not funded. 


\section{Authors' contributions}

AL conceived the manuscript idea. PT and AL implemented the study. PT and WQ drafted the manuscript. AL critically reviewed the draft manuscript. All authors approved the final version.

\section{Acknowledgements}

We are grateful to the organisers of the World Public Health Nutrition Congress 2020 to present this study. The manuscript is an expanded version that presented (virtually) at the Congress.

\section{REFERENCES}

Ababio PF, Adi DD, Amoah M. 2012. "Evaluating the awareness and importance of food labelling information among consumers in the Kumasi metropolis of Ghana.” Food Contr. 26:571-4.

Abarca-Gómez, Leandra, Ziad A Abdeen, Zargar Abdul Hamid, Niveen M Abu-Rmeileh, Benjamin Acosta-Cazares, Cecilia Acuin, Robert J Adams, et al. 2017. "Worldwide Trends in Body-Mass Index, Underweight, Overweight, and Obesity from 1975 to 2016: A Pooled Analysis of 2416 Population-Based Measurement Studies in 128.9 Million Children, Adolescents, and Adults.” The Lancet 390 (10113):2627-42. https://doi.org/10.1016/S0140-6736(17)32129-3.

Bell, Judith, Gabriella Mora, Erin Hagan, Victor Rubin, and Allison Karpyn. 2013. “Access to Healthy Food and Why It Matters: A Review of the Research.” Philadelphia, PA: The Food Trust.

Caspi, E Caitlin, E Jennifer Pelletier, J Lisa Harnack, J Darin Erickson, Kathleen Lenk, and N Melissa Laska. 2017. "Pricing of Staple Foods at Supermarkets versus Small Food Stores." International Journal of Environmental Research and Public Health 14(8):915 https://doi.org/10.3390/ijerph14080915.

Chapman, Kathy, Penny Nicholas, Debbie Banovic, and Rajah Supramaniam. 2006. "The Extent and Nature of Food Promotion Directed to Children in Australian Supermarkets.” Health Promotion International 21 (4):331-39. https://doi.org/10.1093/heapro/dal028.

Darkwa, S. (2014). Knowledge of nutrition facts on food labels and their impact on food choices on consumers in Koforidua, Ghana: A case study. Afr J Clin. Nutr 27(1):13-17.

Euromonitor International (2019). "Retailing in Ghana” https://www.euromonitor.com/retailing-inghana/report

Farquhar, William B, David G Edwards, Claudine T Jurkovitz, and William S Weintraub. 2015. "Dietary Sodium and Health: More than Just Blood Pressure." Journal of the American College of Cardiology 65(10):1042-50. https://doi.org/10.1016/j.jacc.2014.12.039.

Flores, Miguel, and Javier Rivas. 2017. "Cash Incentives and Unhealthy Food Consumption.” Bulletin of Economic Research 69(1):42-56. https://doi.org/10.1111/boer.12085.

French, Simone A. 2003. "Pricing Effects on Food Choices.” The Journal of Nutrition 133(3):841S-843S. https://doi.org/10.1093/jn/133.3.841S.

Freudenberg, Nicholas. 2014. Lethal but Legal: Corporations, Consumption, and Protecting Public Health. Oxford University Press.

Gauthier, Kristine I, and Marilyn J Krajicek. 2013. “Obesogenic Environment: A Concept Analysis and Pediatric Perspective.” Journal for Specialists in Pediatric Nursing : JSPN 18(3):202-10. https://doi.org/10.1111/jspn.12027. 
Ghana Statistical Service -GSS, and Macro International. 1994. "Ghana Demographic and Health Survey 1993.” Calverton, Maryland: GSS and Macro International. https://www.dhsprogram.com/pubs/pdf/FR59/FR59.pdf.

Ghana Statistical Service (GSS), G.H.S., and ICF International. 2015. "Ghana Demographic and Health Survey 2014.” Rockville, Maryland, USA: GSS, GHS, and ICF International. https://dhsprogram.com/pubs/pdf/FR307/FR307.pdf.

Gittelsohn, Joel, Angela Cristina Bizzotto Trude, and Hyunju Kim. 2017. "Pricing Strategies to Encourage Availability, Purchase, and Consumption of Healthy Foods and Beverages: A Systematic Review.” Preventing Chronic Disease 14(November):E107. https://doi.org/10.5888/pcd14.170213.

Hayford F, Steiner-Asiedu M, Sakyi-Dawson E. Food Choice Behaviour among Ghanaians: Implications for Health Promotion. Journal of Nutrition and Health 2015;3(1):22-8.

Hill, James O, Holly R Wyatt, and John C Peters. 2012. "Energy Balance and Obesity.” Circulation 126(1):126-32. https://doi.org/10.1161/CIRCULATIONAHA.111.087213.

Jiang, Shu-Zhong, Wen Lu, Xue-Feng Zong, Hong-Yun Ruan, and Yi Liu. 2016. “Obesity and Hypertension (Review).” Experimental and Therapeutic Medicine 12(4):2395-99. https://www.spandidos-publications.com/etm/12/4/2395.

Kelly, B, L King, L Baur, M Rayner, T Lobstein, C Monteiro, J Macmullan, et al. 2013. "Monitoring Food and Non-Alcoholic Beverage Promotions to Children." Obesity Reviews 14(S1):59-69. https://doi.org/10.1111/obr.12076.

Kessler, David A. 2010. The End of Overeating: Taking Control of the Insatiable American Appetite. Rodale.

Laar, Amos K. 2010. "Family Planning, Abortion, and HIV in Ghanaian Print Media: A 15Month Content Analysis of a National Ghanaian Newspaper.” African Journal of Reproductive Health 14(4 Spec no.):80-86.

León-Muñoz, Luz M, Esther García-Esquinas, Hosanna Soler-Vila, Pilar Guallar-Castillón, José R Banegas, and Fernando Rodríguez-Artalejo. 2016. "Unhealthy Eating Behaviors and Weight Gain: A Prospective Study in Young and Middle-Age Adults.” Obesity 24(5):117884. https://doi.org/10.1002/oby.21477.

Machado, Priscila Pereira, Rafael Moreira Claro, Daniela Silva Canella, Flávia Mori Sarti, and Renata Bertazzi Levy. 2017. "Price and Convenience: The Influence of Supermarkets on Consumption of Ultra-Processed Foods and Beverages in Brazil.” Appetite 116:381-88. https://doi.org/https://doi.org/10.1016/j.appet.2017.05.027.

Naicker, A, C S Venter, U E MacIntyre, and S Ellis. 2015. “Dietary Quality and Patterns and Non-Communicable Disease Risk of an Indian Community in KwaZulu-Natal, South Africa.” Journal of Health, Population, and Nutrition 33(August):12. https://doi.org/10.1186/s41043-015-0013-1.

Ofori-Asenso, Richard, Akosua Adom Agyeman, Amos Laar, and Daniel Boateng. 2016. "Overweight and Obesity Epidemic in Ghana-a Systematic Review and Meta-Analysis." BMC Public Health 16(1):1239. https://doi.org/10.1186/s12889-016-3901-4.

Parfitt, Julian, Mark Barthel, and Sarah Macnaughton. 2010. "Food Waste within Food Supply Chains: Quantification and Potential for Change to 2050.” Philosophical Transactions of the Royal Society B: Biological Sciences 365(1554):3065-81. 
https://doi.org/10.1098/rstb.2010.0126.

Payab, Moloud, Roya Kelishadi, Mostafa Qorbani, Mohammad Esmaeil Motlagh, Shirin Hasani Ranjbar, Gelayol Ardalan, Hoda Zahedi, et al. 2015. "Association of Junk Food Consumption with High Blood Pressure and Obesity in Iranian Children and Adolescents: The CASPIAN-IV Study.” Jornal de Pediatria 91(2):196-205. https://doi.org/10.1016/j.jped.2014.07.006.

Ravensbergen, Eva A H, Wilma E Waterlander, Willemieke Kroeze, and Ingrid H M Steenhuis. 2015. "Healthy or Unhealthy on Sale? A Cross-Sectional Study on the Proportion of Healthy and Unhealthy Foods Promoted through Flyer Advertising by Supermarkets in the Netherlands.” BMC Public Health 15(1):470. https://doi.org/10.1186/s12889-015-1748-8.

Riffe, Daniel, Stephen Lacy, and Frederick G Fico. 1998. “Analyzing Media Messages. Using Quantitative Content Analysis in Research.” London: Lawrence Erlbaum Associates.

Robert Wood Johnson Foundation and The Food Trust. 2011. "Harnessing the Power of Supermarkets to Help Reverse Childhood Obesity."

https://www.rwjf.org/en/library/research/2011/04/harnessing-the-power-of-supermarketsto-help-reverse-childhood-o.html.

Santos Lino, Karoline dos, Cynthia Cristina dos Santos, Diego Brizante dos Santos, Monik Mitsuko Matsumoto, Priscila Pennella Cardoso, Tamyres Matiko Yamamoto, and Giuliana Isabella. 2013. "The Promotion of Flyers and the Consumer Purchase Decision: A Quantitative-Descriptive Research.” PMKT-Brazilian Journal of Marketing, Opinion, and Media Research 13:67-87.

Steenhuis, Ingrid H M, Wilma E Waterlander, and Anika de Mul. 2011. “Consumer Food Choices: The Role of Price and Pricing Strategies.” Public Health Nutrition 14(12):2220 26. https://doi.org/DOI: 10.1017/S1368980011001637.

Swinburn, B, G Sacks, S Vandevijvere, S Kumanyika, T Lobstein, B Neal, S Barquera, et al. 2013. "INFORMAS (International Network for Food and Obesity/Non-Communicable Diseases Research, Monitoring and Action Support): Overview and Key Principles." Obesity Reviews 14(Suppl 1,October): 1-12. https://doi.org/10.1111/obr.12087.

The Rockefeller Foundation. 2013. "Unhealthy Developing World Food Markets." 2013. https://www.rockefellerfoundation.org/report/unhealthy-developing-world-food-markets/.

Umberger, Wendy J, Xiaobo He, Nicholas Minot, and Hery Toiba. 2015. "Examining the Relationship between the Use of Supermarkets and Over-Nutrition in Indonesia." American Journal of Agricultural Economics 97(2):510-25. https://doi.org/10.1093/ajae/aau111.

Ziliani, Cristina, and Silvia Bellini. 2003. "From Loyalty Cards to Micro-Marketing Strategies: Where Is Europe's Retail Industry Heading?” Journal of Targeting, Measurement and Analysis for Marketing 12(3):281-89. https://doi.org/10.1057/palgrave.jt.5740115.

Ziliani, Cristina, and Marco Ieva. 2015. "Retail Shopper Marketing: The Future of Promotional Flyers.” International Journal of Retail \& Distribution Management 43(June):488-502. https://doi.org/10.1108/IJRDM-02-2014-0022. 